\title{
Influence of Biomass Combustion Products on Element Content and Thermal Stability of Latvian Sheep Breed Wool Filter Fibres
}

\author{
Vanda VOIKIVA ${ }^{1}$, Arturs ZARINS ${ }^{1,2}$, Liga AVOTINA ${ }^{1}$, Inesa BARMINA ${ }^{3}$, \\ Vita RUDOVICA ${ }^{4}$, Gunta KIZANE ${ }^{1}$
}

\author{
${ }^{1}$ University of Latvia, Institute of Chemical Physics, Laboratory of Radiation Chemistry of Solids, 1 Jelgavas street, LV-1004, Riga, Latvia \\ ${ }^{2}$ Daugavpils University, Faculty of Natural Science and Mathematics, Department of Chemistry and Geography, la Parades street, \\ LV-5401, Daugavpils, Latvia \\ ${ }^{3}$ University of Latvia, Institute of Physics, 3 Jelgavas street, LV-1004, Riga, Latvia \\ ${ }^{4}$ University of Latvia, Faculty of Chemistry, Department of Analytical Chemistry, 1 Jelgavas street, LV-1004, Riga, Latvia
}

crossref http://dx.doi.org/10.5755/j01.ms.26.4.23942

Received 15 August 2019; accepted 25 November 2019

\begin{abstract}
Sheep wool is natural, easy obtainable, renewable and biodegradable material with a perspective application as a sorbent in filters for purification of industrial emissions from various environmental pollutants. The element content and thermal stability of Latvian dark-headed sheep wool filter fibres was analysed and described before and after exposure to biomass combustion products. Based on the obtained results, it is concluded that the sheep wool filter fibres can sorb various gaseous combustion products, such as carbon monoxide $(\mathrm{CO})$, carbon dioxide $\left(\mathrm{CO}_{2}\right)$ and nitrogen oxides $\left(\mathrm{NO}_{\mathrm{x}}\right)$, however, the sorption processes of these gases are irreversible. The obtained results of total reflection X-ray fluorescence and inductively coupled plasma mass spectrometry suggest that the concentration of heavy metals, such as lead, zinc and iron, significantly increases in the sheep wool filter fibres after exposure to biomass combustion products. In thermogravimetric curves, no significant changes were detected for the sheep wool filter fibres after exposure to combustion products, while in differently thermal analysis curves, the formation of exothermic peak at around $580{ }^{\circ} \mathrm{C}$ was observed and could be related to autoignition. Using X-ray diffractometry and scanning electron microscopy coupled with energy dispersive $\mathrm{X}$ ray spectrometry, the solid particles of biomass combustion products were observed on the scaly surface of the sheep wool filter fibres, and these particles mainly consist of potassium chloride, carbon, sulphur and various metal oxides.

Keywords: sheep wool filter fibres, biomass combustion products, thermal stability, element quantification, surface analysis.
\end{abstract}

\section{INTRODUCTION}

Wool is one of the most important sheep products used for insulation, for the production of building materials, filters, yarns, blankets, clothing, rugs and packaging. However, despite all these uses of wool, sheep farming in Latvia is less profitable. The price of Latvian sheep wool is so low that sheep are mainly raised for meat, but wool is mainly a by-product. The realization of wool is quite difficult as the number of sheep keepers increases, but the demand for wool is constant. Wool marketing is also hampered by the fact that Latvian sheep breeds - Latvian dark-headed (LT) sheep wool - are not suitable and in demand in the textile industry and cannot compete with sheep wool that is directly from wool breed sheep. Currently, there are no factories in Latvia that use sheep wool as the main raw material and therefore it is not really possible to realize it fully. This problem exists not only in Latvia but also in most of the world. There is an increasing demand by customers for finer high quality wool which is used in very fine knit wear and sportswear. However, the demand for stronger and coarse wool is static [1]. Sheep wool is natural, easy obtainable, renewable and biodegradable material, and it mainly consists of structural protein keratin [2]. Latest scientific researches show that sheep wool can easily sorb volatile organic compounds, radionuclides, heavy metals, carbon, nitrogen and sulphur oxides, while the scaly surface of wool fibres can capture solid particles, which can form in combustion processes [3-8]. In addition, sheep wool is very hygroscopic and can sorb humidity from air up to $50 \%$ of its weight [9]. Therefore, sheep wool is used as a sorbent for filters in antipollution masks, appliances, ventilation systems, indoor air filters, healthcare and industrial masks. However, one of the main sources of environmental pollution is industrial emissions. Therefore, the filters consisting of sheep wool for sorption of various environmental pollutants in gas pipes could be relatively inexpensive and biodegradable solution for outdoor air pollution decrease and would support directives of EU to reduce greenhouse gases (GHG) emissions. It would also increase the demand for lower quality wool from sheep of the meat breed and facilitate the efficient use of these wool resources.

Presently, air quality is a very important issue worldwide. It has lately attracted major scientific interest due to global warming. Air pollutants, such as GHG, heavy metals, radionuclides, aerosols etc., can significantly affect world climate and human health by causing heart disease, lung cancer and chronic respiratory diseases. And it is

\footnotetext{
${ }^{*}$ Corresponding author. Tel.: +371-670-33937.

E-mail address: vanda.voikiva@lu.lv(V. Voikova)
} 
important to reduce these emissions in such a way that not cause other types of pollution.

\section{EXPERIMENTAL}

Samples of wool for chemical analysis were clipped in the ribs at the palm of the forelegs. The wool samples were collected according to Australian Standard AS/NZ 4492.1, from the Latvian dark-headed breed sheep with similar age (2-4 years) and same gender (female). Various sheep wool fibres cleaning methods were compared [9-11], and an optimal method was selected and applied in this study. The collected sheep wool fibres were washed with detergent (soap with surfactants) in warm water $\left(50-60^{\circ} \mathrm{C}\right)$ and were dried at room temperature in air for several hours. After the described cleaning process, the sheep wool fibres (weight: $\sim 5 \mathrm{~g}$ ) were placed uniformly in aluminium sieve shape filter form (diameter: $10 \mathrm{~cm}$, length: $1 \mathrm{~cm}$ ). The sorption of biomass combustion products in sheep wool filter fibres was studied using laboratory-scale experimental system at the Institute of Physics of the University of Latvia (Fig. 1). The commercial wheat straw pellets ("EkoGrans" Ltd., WUBIONET - European pellets standard 14961-6, weight: $\sim 450 \mathrm{~g}$ ) were air to produce various gaseous and solid combustion products. To initiate the process of gasification and combustion of straw pellets, was used propane. After volatile compounds ignite (470 seconds), the propane supply was interrupted, and a self-sustaining process of straw burning occurs. The combustion process of biomass was continued up to $50 \mathrm{~min}$. The concentration of gaseous combustion products was continuously monitored by Testo $350 \mathrm{XL}$ portable combustion gas analyser.

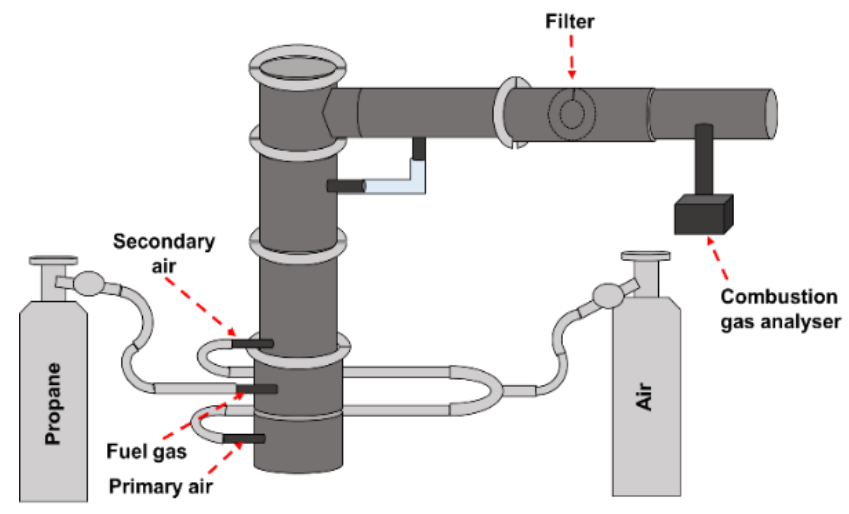

Fig. 1. Laboratory-scale experimental system for sorption analysis of biomass combustion products

$\mathrm{CO}_{2}$

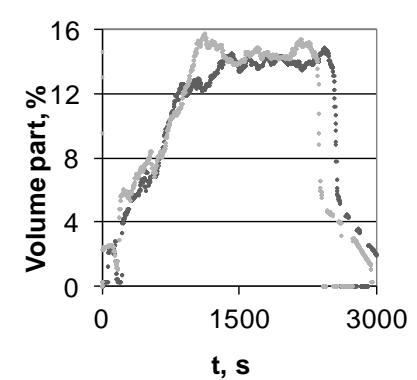

CO

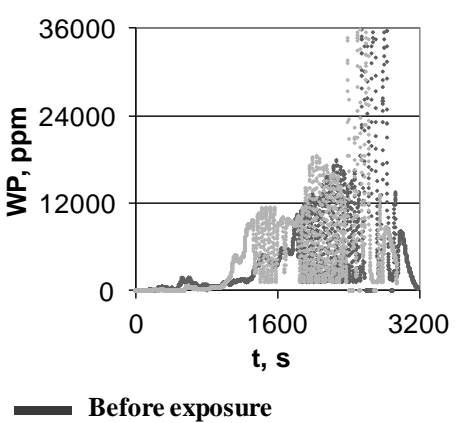

The element content of the sheep wool filter fibres before and after exposure to biomass combustion products was studied by TXRF (Bruker S2 PICOFOX portable benchtop spectrometer, Mo anode X-ray tube, max. power: $50 \mathrm{~W}, \mathrm{Si}$ drift flash detector, area: $300 \mathrm{~mm}^{2}$; FWHM: $<150 \mathrm{keV}$, $\mathrm{MnK}_{\alpha}$, analysis time: $300 \mathrm{sec}$ ) and ICP-MS (Triple Quad Agilent Technologies 8900: power 1550W. For the TXRF and ICP-MS measurements, the sheep wool filter fibres were dried in oven at around $60{ }^{\circ} \mathrm{C}$ for two days in order to achieve complete water evaporation. The dried sheep wool fibres with weight $0.5000 \mathrm{~g}$ were dissolved in mixture of 5 $\mathrm{mL}$ concentrated nitric acid and $4 \mathrm{~mL}$ of hydrogen peroxide and were mineralized using microwave energy at temperature $130{ }^{\circ} \mathrm{C}$. The resulting solution was diluted up to $25 \mathrm{~mL}$ volume with deionized water.

The surface morphology of the sheep wool filter fibres was analysed by SEM Hitachi S4800. The thermal stability was studied by TG/DTA EXSTAR $6300\left(20-900{ }^{\circ} \mathrm{C}\right.$, $10^{\circ} \mathrm{C} / \mathrm{min}$, nitrogen or air, nitrogen flow: $150 \mathrm{~mL} / \mathrm{min}$ ). The gaseous decomposition products were investigated by TG/DTA coupled with FT-IR spectrometer (Bruker Vertex $70 \mathrm{v}, 20-900{ }^{\circ} \mathrm{C}, 90{ }^{\circ} \mathrm{C} / \mathrm{min}, 150 \mathrm{~mL} / \mathrm{min}$ nitrogen flow, $\pm 4 \mathrm{~cm}^{-1}$ resolution, 32 scans). The solid particles of biomass combustion products were mechanically removed from the surface of sheep wool filter fibres and were analysed by XRD (Bruker D8, $\mathrm{CuK}_{\alpha}$, range: $10-70^{\circ} 2 \theta$, scan speed: $0.05^{\circ} 2 \theta$, scan time: $5 \mathrm{sec}$ ) and SEM coupled with EDX system Bruker Xflash Quad 5040; $123-\mathrm{eV}$.

\section{RESULTS AND DISCUSSION}

\subsection{Evaluation of biomass gaseous combustion products}

In the biomass combustion processes, various gaseous compounds are forming, such as carbon monoxide (CO), carbon dioxide $\left(\mathrm{CO}_{2}\right)$, sulphur dioxide $\left(\mathrm{SO}_{2}\right)$, nitrogen oxides $\left(\mathrm{NO}_{\mathrm{x}}\right)$ etc. The concentration of $\mathrm{CO}_{2}, \mathrm{NO}_{2}$ and $\mathrm{NO}_{\mathrm{x}}$ before and after insertion of the sheep wool filter fibres in the laboratory-scale experimental system is shown in Fig. 2. The obtained results show slight changes after insertion of the sheep wool filter fibres in the system. The main differences are in the quantity of $\mathrm{NO}_{\mathrm{x}}$. The concentration of $\mathrm{NO}_{\mathrm{x}}$ decreases up to $10 \%$ at the beginning of the biomass combustion process, while in the middle and end it reached up to $30 \%$ decrease. The reason, what explain these differences is slow reaction rate of nitrogen oxides with
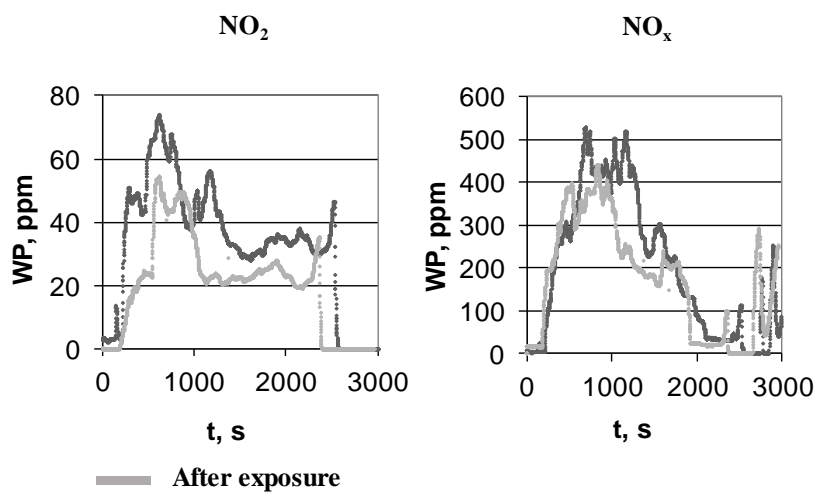

Fig. 2. Quantity of biomass gaseous combustion products before and after insertion of the sheep wool filter fibres in the laboratory-scale experimental system 
keratin molecules, which is rised by temperature increase in the experimental system (from around $80{ }^{\circ} \mathrm{C}$ to $100{ }^{\circ} \mathrm{C}$ ), what positively improve the sorption process. Evaluating the $\mathrm{CO}$ release rate, an increase in the middle and end stage of the combustion process was detected, which could be caused by oxygen deficiency, resulting in uncomplete burning process of biomass. The concentration of $\mathrm{CO}_{2}$ increase is approximately $2 \%$ and can be attributed to heterogeneous composition of wheat straw pellets.

\subsection{Surface morphology of sheep wool filter fibres}

The surface of the sheep wool filter fibres before exposure to biomass combustion products is uneven with scaly shape elements, different surface roughness and damages (Fig. 3).
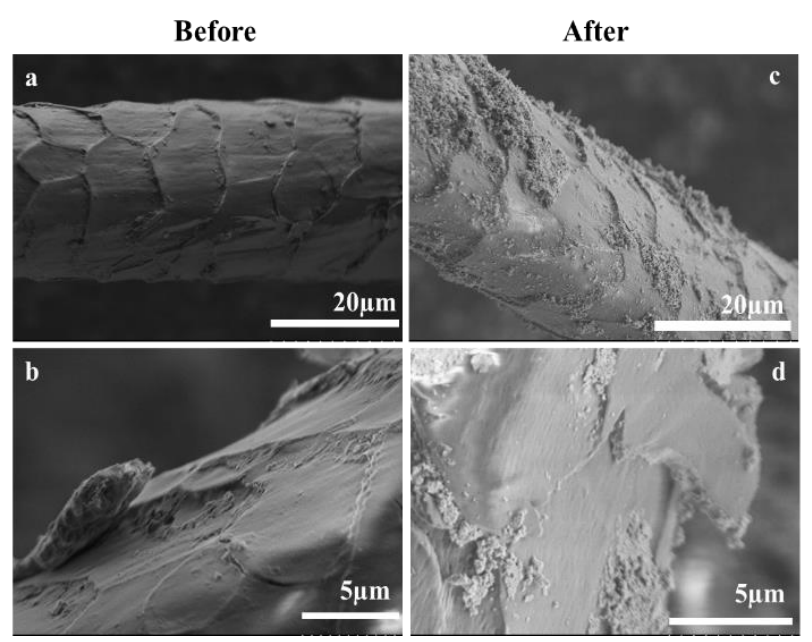

Fig. 3. a, b-SEM images of the sheep wool filter fibres before and c, $d$-after exposure to biomass combustion products
The examined sheep wool filter fibres have a diameter between $20 \mu \mathrm{m}$ and $40 \mu \mathrm{m}$ (average value: $\sim 30 \mu \mathrm{m}$ ). The high number of pores and surface roughness of the wool fibres correlates with specific surface area and thereby with sorption capacity [8]. After exposure to biomass combustion products, no major changes were detected for the sheep wool filter fibres, which could be attributed to the sorption experiment. This shows that the suitability of sheep wool fibres as a potential material for filters and possible further application in such studies. In addition, the solid particles were observed on the surface of sheep wool filter fibres after exposure to combustion products. The element composition and phase composition of these particles is analysed and described in the Chapter 3.5.

\subsection{Element content of sheep wool filter fibres}

The analysed sheep wool filter fibres before exposure to biomass combustion products contain various elements, such as sulphur, potassium, calcium, chromium, manganese, iron, cobalt, nickel, copper, zinc, lead, cadmium etc. The obtained ICP-MS and TXRF results of the sheep wool filter fibres before and after exposure to biomass combustion products are shown in Fig. 4 and Fig. 5, respectively. The obtained results before exposure to combustion products correlates with the literature data [10]. However, the amount of such metals as arsenic, tin, cadmium, cobalt and chromium, deviates from the literature but can be explained by differences in environmental quality. Comparing sulphur content in analysed samples with literature data, the amount of it was significantly higher, which may indicate an erroneous result, since sulphur is a light element and the sensitivity of the apparatus to it is not very high. Also, the accuracy and accuracy of the measurements is affected by the fact that the molybdenum spectral line overlaps slightly with the sulphur spectral line, and thus the machine shows elevated results.

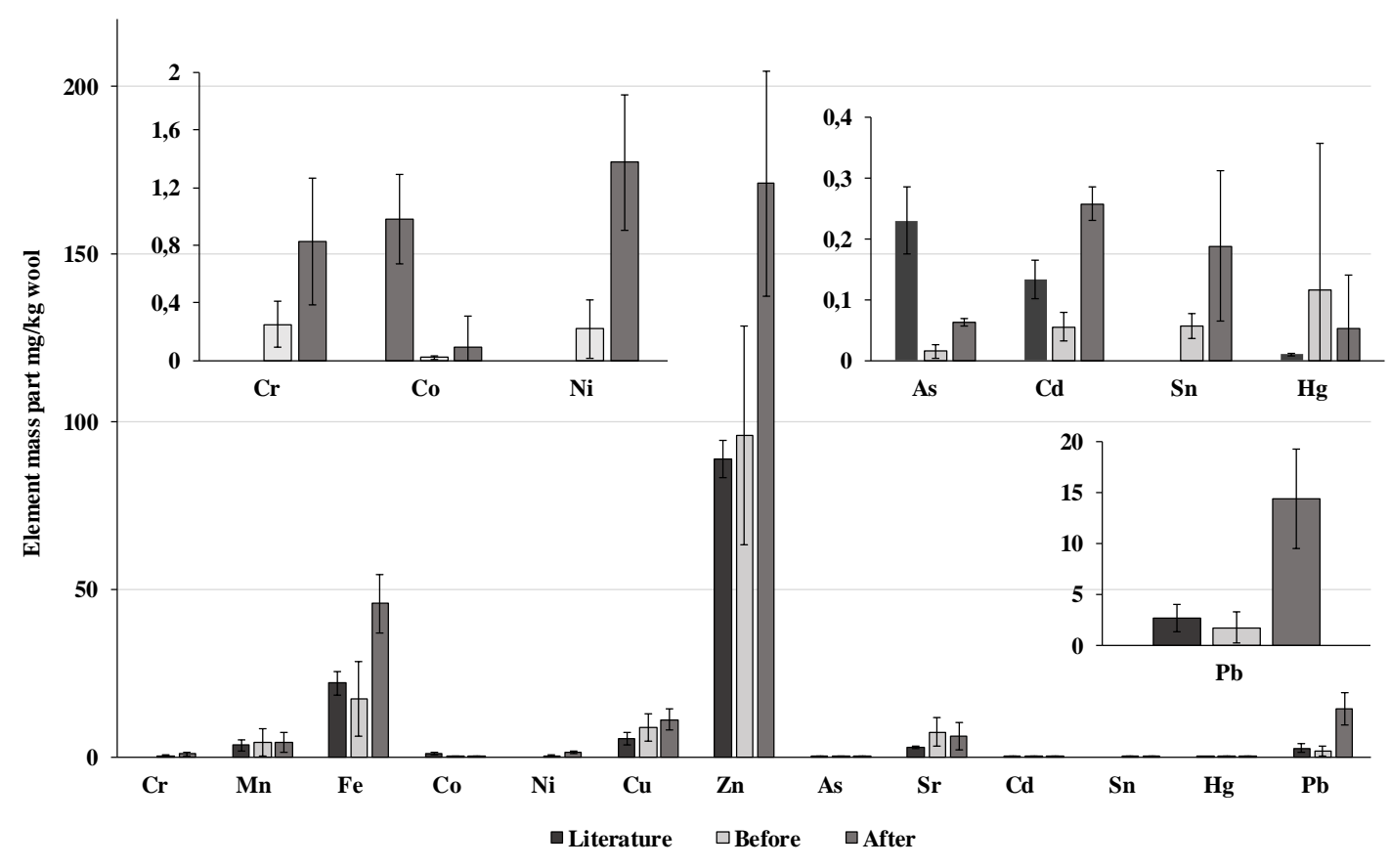

Fig. 4. ICP-MS data: element content of the sheep wool filter before and after exposure to biomass combustion products (light and dark grey bars) and literature data (black bars) 


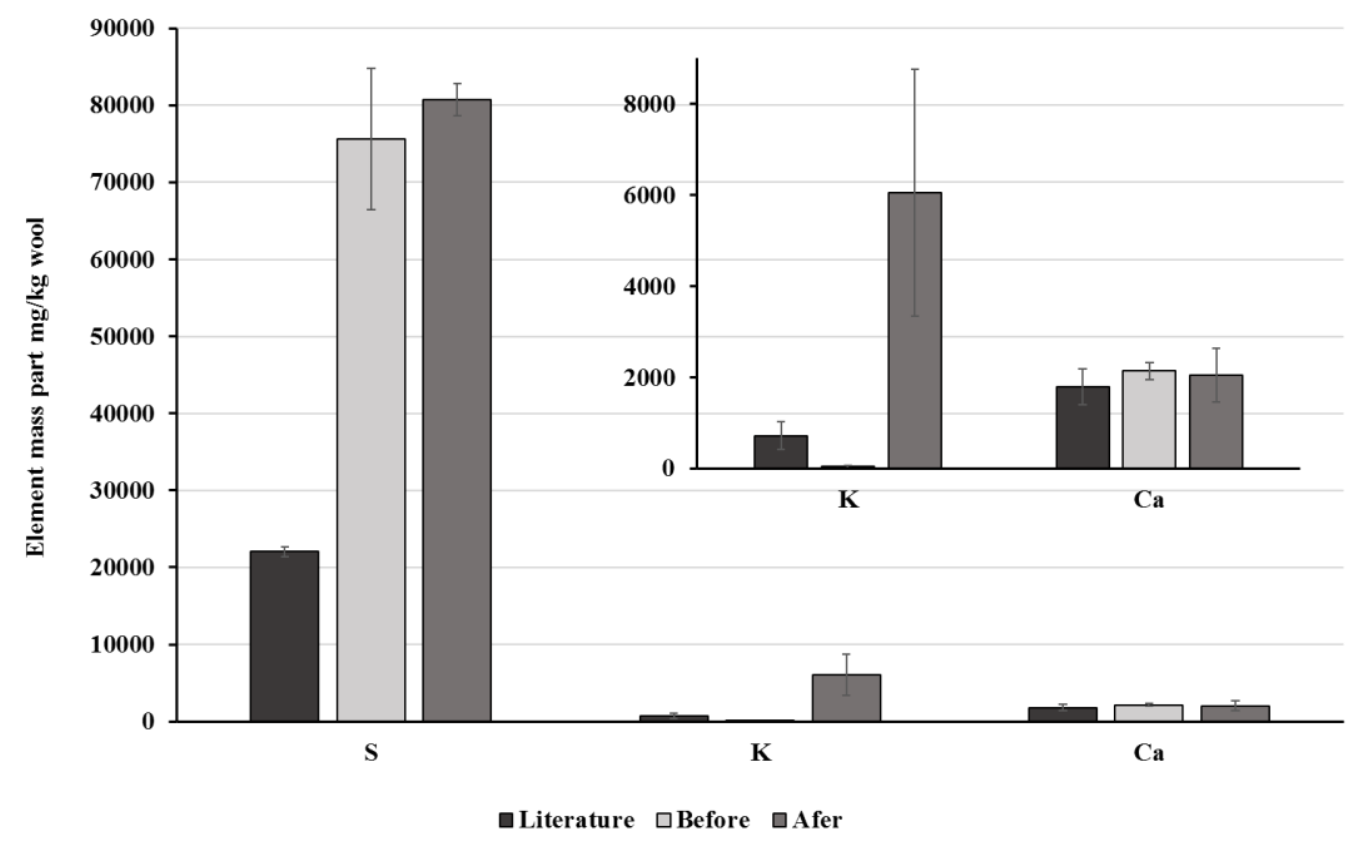

Fig. 5. TXRF data: element content of the sheep wool filter before and after exposure to biomass combustion products (light and dark grey) and literature data (black bars)

However, we can't say with certainty that the data is incorrect because other sheep wool has been studied in the literature, and there is a fairly significant dispersion of results between other countries.

Nevertheless, the concentration of these elements can be affected by sheep age, growth region/country and forage and thereby can explain negligible variations.

After exposure to biomass combustion products, significant increase of lead, zinc, nickel, cadmium, iron and potassium concentration was detected in the sheep wool filter fibres, while for other elements (calcium, sulphur, arsenic, copper and mercury) increase is negligible. The increased concentration of lead, zinc, nickel, cadmium, iron and potassium can be attributed to wheat straw pellets and selective sorption of these metals by the sheep wool filter fibres. Many metals, such as lead, can form organometallic compounds, which have good solubility [12]. The metal ions, which may form due to dissolution in water, may react with keratin molecule side chains replacing the hydrogen atoms from-OH groups [14]. The wool sorption capacity of various elements is described in literature [8], and this data shows that the largest capacity is for mercury, silver, lead and platinum ions (>100 mg per $1 \mathrm{~kg}$ of sheep wool). Nevertheless, the sorption capacity of these metal ions depends factors, such as $\mathrm{pH}$, temperature, flow rate etc.

\subsection{Thermal stability and decomposition products of sheep wool filter fibres}

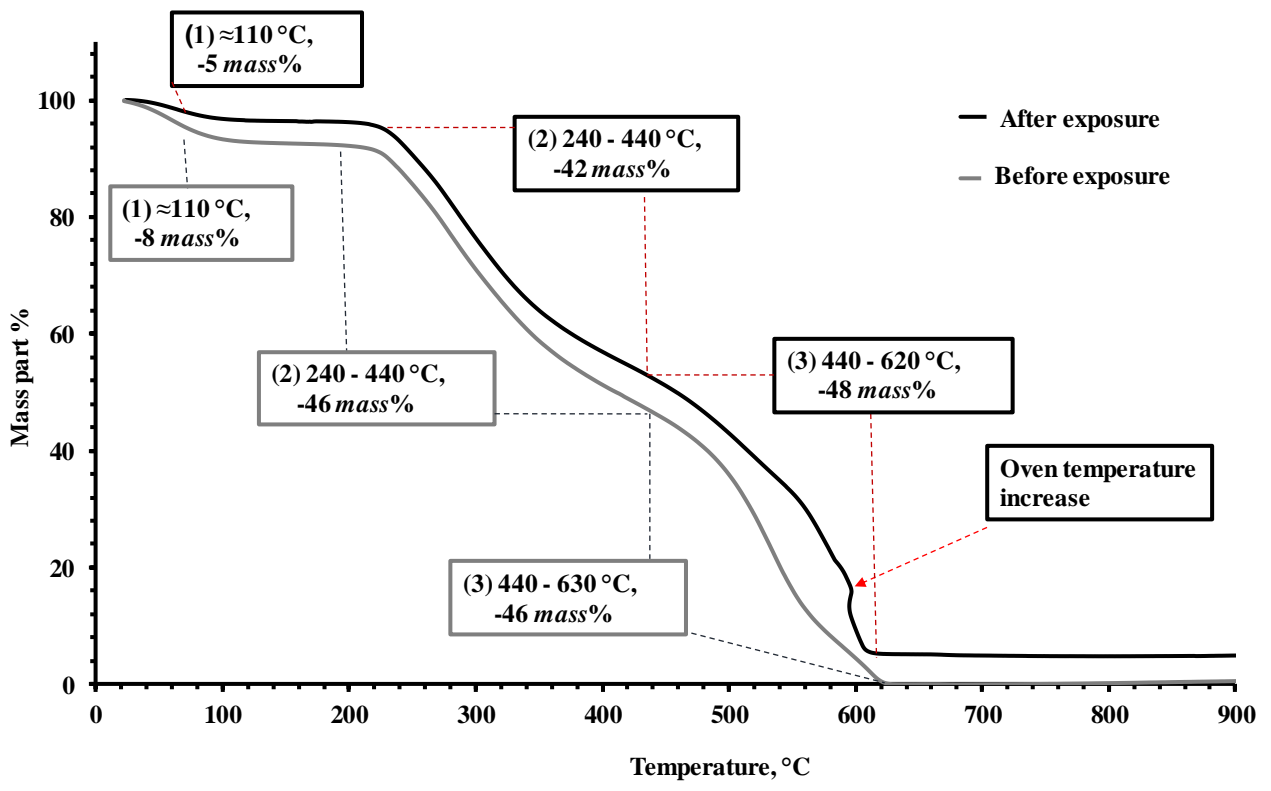

Fig. 6. TG curves of the sheep wool filter fibres before and after exposure to biomass combustion products 


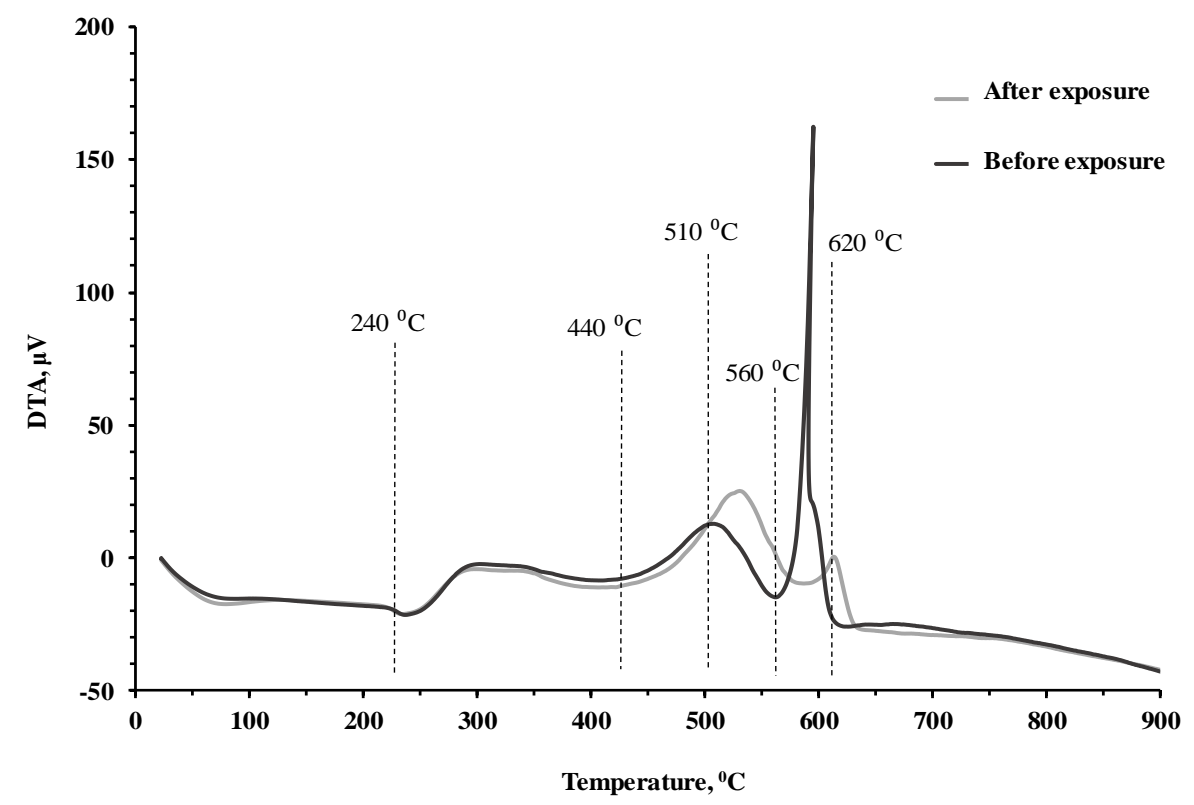

Fig. 7. DTA curves of the sheep wool filter fibres before and after exposure to biomass combustion products

The obtained TG, DTA and DTG (differential thermogravimetry) curves confirm that the sheep wool filter fibres before exposure to combustion products is heat resistant up to $230{ }^{\circ} \mathrm{C}$ (Fig. 6 and Fig. 7). The slight decrease of weight up to $100{ }^{\circ} \mathrm{C}$ can be attributed to desorption of water from the surface of sheep wool filter fibres.

Second decomposition process $\left(240-440{ }^{\circ} \mathrm{C}\right)$ can be related to protein denaturation process and various side chains losing, while third process $\left(400-630^{\circ} \mathrm{C}\right)$ can be attributed to complete and semi-complete oxidation of amino acids and other products. Comparing the obtained TG, DTA and DTG curves of the sheep wool filter fibres before and after exposure to biomass combustion products, significant changes were not detected up to $480{ }^{\circ} \mathrm{C}$. The most notable difference was observed in the final decomposition process, where very rapid enthalpy and weight changes were detected at about $590{ }^{\circ} \mathrm{C}$. Most likely this effect can be related to auto-ignition [15].

Repeating this process in nitrogen atmosphere such exothermic signal was not detected, what also confirms this suggestion. The auto-ignition process can be caused by nitro group adding to keratin molecules and their flammability. In the FTIR spectra of the gaseous decomposition products for the sheep wool filter fibres before and after exposure of biomass combustion products, the main signals occur corresponding to the TG three weight decrease steps. The main FTIR signals occur at around $750 \mathrm{~cm}^{-1}$ and $2330-2360 \mathrm{~cm}^{-1}\left(\mathrm{CO}_{2}\right)$ [14] and at around 1660 and $3300 \mathrm{~cm}^{-1}\left(\mathrm{H}_{2} \mathrm{O}\right)$. The obtained FTIR of the gaseous decomposition products for the sheep wool filter fibres before exposure of combustion products is shown in Fig. 8. An analysis of the breakdown products of wool is necessary to assess the safety of a filter made of such material. The main signals of the FTIR spectra can be interpreted as follows:
- The stretching of $\mathrm{O}-\mathrm{H}$ bonds in water molecules is between 3200 and $3700 \mathrm{~cm}^{-1}$ and between 1200 and $1500 \mathrm{~cm}^{-1}$;

- Fluctuations of $\mathrm{N}-\mathrm{O}$ bonds in the $\mathrm{NO}_{2}$ molecule are attributed to the signal $1600-1800 \mathrm{~cm}^{-1}$;

- $1200-1350 \mathrm{~cm}^{-1}$ signal refers to the oscillation of $\mathrm{S}-\mathrm{O}$ bonds in the $\mathrm{SO}_{2}$ molecule;

- $1950-2100 \mathrm{~cm}^{-1}$ refers to the $\mathrm{CO}$ molecule of bond oscillations;

- Amide (NH stretching) from 3075 to $3056 \mathrm{~cm}^{-1}$;

- The maxima from 2200 to $2400 \mathrm{~cm}^{-1}$ and from 900 to $1000 \mathrm{~cm}^{-1}$ are $\mathrm{C}=\mathrm{O}$ vibrations in the $\mathrm{CO}_{2}$ molecule;

- The signal from 2800 to $3000 \mathrm{~cm}^{-1}$ is due to vibration of $\mathrm{C}-\mathrm{H}$ bonds;

- $\mathrm{H}-\mathrm{S}$ bond fluctuations are observed at $1570 \mathrm{~cm}^{-1}$.

The bond fluctuations seen in the FTIR spectrum indicate a number of compounds, both organic and inorganic, such as $\mathrm{NO}_{2}, \mathrm{SO}_{2}, \mathrm{CO}_{2}, \mathrm{CHNO}$, etc. excretion.

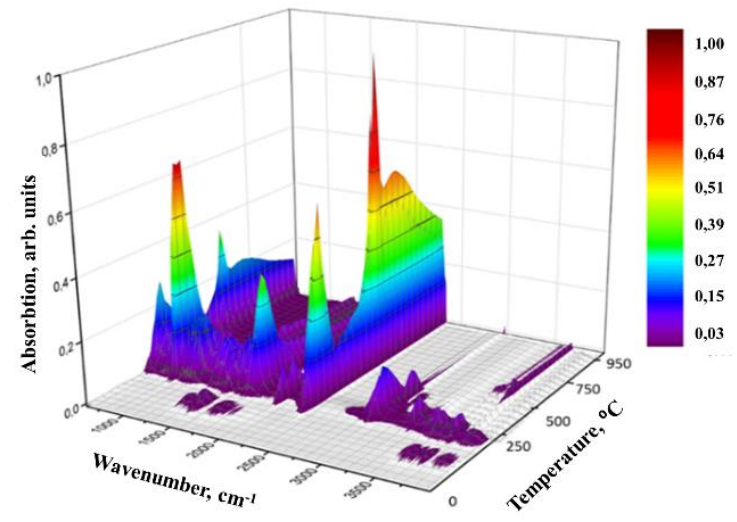

Fig. 8. FTIR spectra of the sheep wool filter fibres decomposition gaseous compounds at nitrogen atmosphere 


\subsection{Solid particles of biomass combustion products}

During the biomass combustion proceses, it was detected that the sheep wool filter fibres can capture solid particles due to the scaly surface. The solid particle agglomerates with size larger than $40 \mu \mathrm{m}$ were mechanically removed from the surface of wool filter fibres. The obtained SEM images of these particles are shown in Fig. 10. The agglomerates consist of smaller particles with size less than $2 \mu \mathrm{m}$.

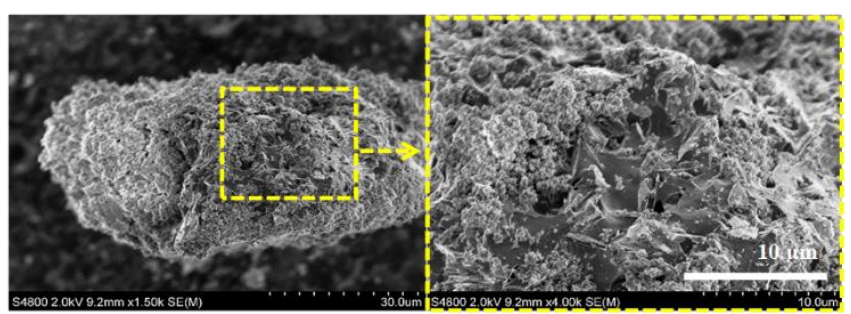

Fig. 10. SEM images of the removed solid particles from the surface of the sheep wool filter fibres, which are forming in biomass combustion process

The obtained results of SEM-EDX spectrometry and XRD indicate that the solid particles have heterogeneous structure and chemical composition. Using XRD method, it was confirmed that the solid particles mainly consist of potassium chloride. The SEM-EDX spectrometry showed that the chemical element content is in following order: $\mathrm{C}>$ $\mathrm{O}>\mathrm{K}>\mathrm{Cl}>\mathrm{N}>\mathrm{S}>\mathrm{Mg}>\mathrm{Si}$.

\section{CONCLUSIONS}

On the basis of the obtained results, it is concluded that the Latvian dark-headed sheep's wool fibres have a potential to be used as a potential sorbent material for GHG and solid particles, which can form during combustion processes. The sheep's wool fibres are heat resistant up to $230{ }^{\circ} \mathrm{C}$ and can be used in filtration systems up to $200{ }^{\circ} \mathrm{C}$. They reduce the amount of GHG generated by the burning processes and prevent the emission of solid particles. The sheep wool fibres are capable to sorb iron, zinc, cadmium, lead and nitrogen oxides $\left(\mathrm{NO}_{\mathrm{x}}\right)$. After the sorption of $\mathrm{GHG}$, the sheep's wool fibres have an auto-ignition point at around $580{ }^{\circ} \mathrm{C}$ temperature.

\section{Acknowledgments}

The work is performed in the frames of the University of Latvia financed project No. Y9-B044-ZF-N-300, "Nano, Quantum Technologies, and Innovative Materials for Economics", in collaboration with experts from association "Latvian Sheep Breeders Association".

\section{REFERENCES}

1. Walker, J. Wool and Sheep Production in the Global Market A Report for 2008 No. March Nuffield Scholar 2008: pp. 30.
2. Bradbury, J.H. The Morphology and Chemical Structure of Wool Pure and Applied Chemistry $46(2-4)$ 2007: pp. $247-253$. https://doi.org/10.1351/pac197646020247

3. Curling, S.F., Loxton, C., Ormondroyd, G.A. A Rapid Method for Investigating the Absorption of Formaldehyde from Air by Wool Journal of Materials Science 47 (7) 2012: pp. $3248-3251$. https://doi.org/10.1007/s10853-011-6163-7

4. Huang, X., Wang, Y.J., Di, Y.H. Experimental Study of Wool Fiber on Purification of Indoor Air Textile Research Journal 77 (12) 2007: pp. 946-950 https://doi.org/10.1177/0040517507083519

5. Monier, M., Ayad, D.M., Sarhan, A.A. Adsorption of $\mathrm{Cu}(\mathrm{II}), \mathrm{Hg}(\mathrm{II})$, and $\mathrm{Ni}(\mathrm{II})$ Ions by Modified Natural Wool Chelating Fibers Journal of Hazardous Materials 2010: pp. $348-355$. https://doi.org/10.1016/j.jhazmat.2009.11.034

6. Ghosh, A., Collie, S.R. Keratinous Materials as Novel Absorbent Systems for Toxic Pollutants Defence Science Journal 64 (3) 2014: pp. 209-221. https://doi.org/10.14429/dsj.64.7319

7. Radetic, M., Jocic, D., Jovancic, P., Rajakovic, L. Sorption Properties of Wool Hemijska industrija $58(7-8)$ 2008: pp. 315-321. DOI: 10.2298/HEMIND0408315R

8. Mansour, E. Wool Fibres for the Sorption of Volatile Organic Compounds (VOCs) from Indoor Air Being a Thesis Submitted in Candidature by. 2017.

9. Norvele, G., Neilands, I., Matisāns, E. Sheep Farming LUA Ulbrock Science Center 2001: pp. 42-55. (in Latvian).

10. Patkowska-Sokola, B., Dobrzanski, Z., Osman, K., Bodkowski, R., Zygadlik, K. The Content of Chosen Chemical Elements in Wool of Sheep of Different Origins and Breeds Archives Animal Breeding 52 (4) 2009: pp. $410-418$. https://doi.org/10.5194/aab-52-410-2009

11. Branisa, J., Jomova, K., Porubska, M. Scouring Test of Sheep Wool Intended for Sorption Fibres \& Textiles in Eastern Europe 27 (2) 2019pp. 24-29. https://doi.org/10.5604/01.3001.0012.9983

12. Hashem, T., Abbas, H., Farid, I.M., Hassan, M., Abbas, H. Accumulation of Some Heavy Metals in Plants and Soils Adjacent to Cairo - Alexandria Agricultural Highway. 2017, No. March 2019. https://doi.org/10.21608/ejss.2016.281.1047

13. Hanzlíková, Z., Braniša, J., Jomová, K., Fülöp, M., Hybler, P., Porubská, M. Electron Beam Irradiated Sheep Wool - Prospective Sorbent for Heavy Metals in Wastewater Separation and Purification Technology 193 2018: pp. $345-350$ https://doi.org/10.1016/j.seppur.2017.10.045

14. Schadle, T., Pejcic, B., Mizaikoff, B. Monitoring Dissolved Carbon Dioxide and Methane in Brine Environments at High Pressure using IR-ATR spectroscopy Analytical Methods 8 2016: pp. $756-762$ https://doi.org/10.1039/C5AY02744F

15. Ingham, P.E. Fire safety of wool carpets for public buildings, WRONZ Technical Bulletin, 1999.

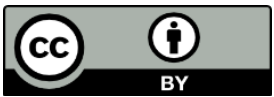

(C) Voikiva et al. 2020 Open Access This article is distributed under the terms of the Creative Commons Attribution 4.0 International License (http://creativecommons.org/licenses/by/4.0/), which permits unrestricted use, distribution, and reproduction in any medium, provided you give appropriate credit to the original author(s) and the source, provide a link to the Creative Commons license, and indicate if changes were made. 